\title{
BÍBLIA E PASTORAL DA MOBILIDADE HUMANA
}

Bible and Pastoral Care of Human Mobility

Elizangela Chaves Dias*

Resumo. O cenário da mobilidade humana tem proporcionado amplo espaço para reflexões, debates e elaborações nas diversas áreas do conhecimento, referentes à realidade e demanda da migração forçada e refúgio. Esse artigo propõe-se a apresentar uma abordagem sobre a temática da animação bíblica e mobilidade humana, buscando nas experiências e nos personagens das narrativas bíblicas modelos para uma prática pastoral efetiva e eficaz junto a migrantes e refugiados.

Palavras-chave: Bíblia, migração, refúgio, pastoral.

Abstract. The human mobility scenario has provided ample space for reflections, debates and elaborations in the different areas of knowledge, referring to the reality and demand of forced migration and refuge. This article proposes to present an approach on the theme of biblical animation and human mobility, seeking in the experiences and in the biblical narratives the models for an effective and effective pastoral practice among migrants and refugees.

Keywords: Bible, migration, refuge, pastoral.

* Scalabrini International Migration Institute (SIMI) - Roma. Roma, Itália. 


\section{Introdução}

O cenário da mobilidade humana tem proporcionado amplo espaço para reflexões, debates e elaborações nas diversas áreas do conhecimento, referentes à realidade e às demandas da migração forçada e refúgio. Também no campo das ciências teológicas sente-se a necessidade de novas reflexões sobre migração e refúgio desde suas mais diversas facetas, que contribuam para uma prática pastoral efetiva e eficaz. De tal modo, surgem notórias contribuições acadêmicas numa nova área do saber teológico denominada teologia das migrações, a fim de responder às inquietações decorrentes do impacto do fenômeno das migrações e refúgio, na sociedade e na igreja do século XXI'.

Nesse contexto, a abordagem do tema sobre animação bíblica e mobilidade humana é, ao mesmo tempo, fascinante e desafiadora, devido aos inúmeros temas que dele decorrem ou a ele se relacionam. Por exemplo: universalidade e particularidade da eleição de Deus; promessas e aliança divinas; tolerância e intolerância; o estrangeiro e o imigrante; a multiculturalidade e a diversidade religiosa; o amor e o ódio; a inclusão e a exclusão; a justiça e a injustiça; a vida e a morte; os conflitos e as violências; o isolamento e o acolhimento; o medo e a estima pela diversidade; a perda da terra e outros.

A Bíblia é uma coleção de livros e, como toda biblioteca, possui escritos com ideologias e políticas diferentes. A beleza desta coleção de livros está justamente no fato de que os pensamentos diferentes não foram excluídos, pois a inclusão possibilita o diálogo e rompe as fronteiras nas vias da salvação. Entre outros, é possível citar os livros de Esdras e de Rute como exemplos clássicos do confronto entre ideologias exclusivistas e universalistas referentes à eleição, bênção e salvação.

Esdras, escriba encarregado dos negócios judaicos na corte da Pérsia, conclui que o prejuízo do antigo Israel deve-se ao fato de ter se deixado influenciar pela cultura, crenças e práticas dos povos com os quais convivia, a ponto do povo eleito esquecer sua identidade. Para Esdras, um dos pontos centrais do infortúnio do povo eleito se deve aos matrimônios mistos (cf. Esd 9,1-2; 10,5; Ne 13,23-31); por isso, em sua política de retorno do exílio à terra da promessa, ele fomenta uma ideologia separatista. Todos os homens do povo de Israel que tivesse desposado mulheres estrangeiras deveriam despedi-las com seus filhos, impiedosamente (cf. Esd 10,1-44).

\footnotetext{
1 Cf. CAMPESE, Gioacchino. Não és mais estrangeira nem hóspede: A teologia das migrações no século XXI; FUMAGALLI, Anna. Ler a Bíblia no contexto migratório. Os autores oferecem uma vasta bibliografia, acompanhada de uma análise dos argumentos abordados nas diversas publicações.
} 
Em contrapartida, o livro de Rute teria sido escrito para contestar as determinações religiosas, políticas e sociais refletidas no livro de Esdras. De tal modo, a lembrança do majestoso rei Davi e de seu vínculo familiar com Rute, uma estrangeira moabita, serviriam de argumento para afirmar que nem todas as mulheres estrangeiras, que se fixaram em Israel através do matrimônio misto, transgrediram a fé ou causaram efeitos perniciosos ao povo eleito².

A presença desses dois livros, com suas respectivas ideologias, no conjunto dos textos do Antigo Testamento, além de possibilitar o diálogo sobre o tema da universalidade da salvação e da abertura de Israel aos povos estrangeiros, põe em foco o tema da conversão ao Deus de Israel (cf. Rt 1,16-17).

Essas, porém, não são as únicas perspectivas sobre as quais é possível abordar o tema da mobilidade humana na Bíblia. Com efeito, a Bíblia se revela uma fonte de inspiração extremamente rica, por isso o presente artigo, sem pretender exaurir, objetiva evidenciar na primeira parte uma visão da temática migratória na Bíblia e, na segunda parte, oferecer sugestões para o serviço pastoral com migrantes a partir e com a Bíblia.

\section{Testemunho bíblico}

\subsection{Os patriarcas e a experiência da migração}

O Antigo Testamento revela o caminhar de Deus com o humano e do humano com Deus, num processo dialógico de amadurecimento da compreensão recíproca. O tema da criação e da história universal da humanidade, retratado nos primeiros onze capítulos do livro do Gênesis, se insere nessa lógica.

O tema da criação tornou-se fundamental quando o antigo Israel encontrava-se exilado na Babilônia (586-536 a.C.) ${ }^{3}$. Durante os cinquenta anos de exílio as narrativas e as tradições ancestrais tomaram a forma que se conhece hoje, descrevendo a origem do universo, dos povos e das línguas (cf. Gn 1-11); e as origens do povo de Israel (cf. Gn 12-50). Israel havia perdido seu país, seu templo, seu rei e estava numa terra estrangeira. Para os exilados, esses fatos poderiam significar que o seu Deus fora vencido, não tivera força para

\footnotetext{
Cf. FERNANDES, Leonardo Agostini. Rute, p. 16-18.

Cf. SKA, Jean-Louis. O canteiro do Pentateuco, p. 24. A região habitada pelo antigo Israel encontra-se num corredor que interliga o Egito e a Mesopotâmia, grandes potências do tempo. O território de Israel foi invadido e dominado por essas potências mais de uma vez. Três eventos são essenciais a respeito da ameaça dos povos fronteiriços a Israel: 1) o fim do reino de Samaria e sua integração no reino neo-assírio em 722 a.C.; 2) a invasão do rei assírio Senaqueribe em 701 a.C. e o cerco de Jerusalém (cf. 2 Rs 18,14); 3) os dois cercos de Jerusalém em 598/597 e em 588/587 a.C., com a queda da Cidade Santa, diversas deportações, transformando o reino de Judá em província do Império Babilônico.
} 
defender seu povo e sua terra. A eliminação de Israel da carta geográfica dos povos representava uma terrível tentação para a fé do antigo Israel ${ }^{4}$.

O exílio, porém, não significou o fim, mas oportunidade para elaborar um novo começo. A ausência de um rei, de um templo e da própria terra estimulou a reflexão sapiencial sobre a origem do mundo, da humanidade e da origem de Israel. Sob inspiração divina, a classe sacerdotal afirma a soberania de Deus criador do universo e da humanidade, onipotente e transcendente que cria com sua Palavra (cf. Gn 1,1-2,4a) $)^{5}$. Numa segunda versão do relato da criação, Deus se revela como um jardineiro, que vai separando os elementos do universo, criando um belo jardim para nele colocar os progenitores do ser humano, Adão e Eva; nomes que significam, respectivamente, "tirado do solo" e "mãe dos viventes" (cf. Gn 2,7; 3,20). Os dois relatos trazem uma visão positiva, pois todo o universo criado é belo e foi colocado à disposição da humanidade ${ }^{6}$.

Todos os tipos de plantas e de animais foram criados "segundo a sua espécie" (cf. Gn 1,11.12.21.24.25; 6,20; 7,14). O gênero humano é criado à imagem e semelhança de Deus (cf. Gn 1,26). Não há espécies no gênero humano, ele é uno e um só. Também não há diferenças entre homem e mulher, porque o texto evidencia com clareza: "Deus criou o homem e a mulher à sua imagem e semelhança, à imagem de Deus o criou, macho e fêmea Ele os criou" (Gn 1,27). O relato da criação nega, desde o princípio, qualquer diferença entre etnias, raças humanas, classes sociais ou superioridade de gênero ${ }^{7}$.

Como entender, então, que o ser humano experimenta sentimentos de aversão em relação ao seu semelhante, estranhamento em relação ao seu ser no mundo e distância em relação a Deus? Segundo a narrativa bíblica, o ser humano, pela desobediência, rompeu seu vínculo com o $\mathrm{Criador}^{8}$. Em decorrência de seus atos, o ser humano passa a conviver com uma nova condição existencial: o exílio e a dispersão. Adão e Eva são exilados do jardim (cf. Gn 3,23). A violência e as injustiças se tornam incontroláveis e se alastram pelo mundo (cf. Gn 4,1-5,7).

O centro desta história, no entanto, se encontra na misericórdia de Deus. O exílio, que conduz a humanidade à morte, será ao mesmo tempo um "caminho de resgate". Com a eleição de Abraão (cf. Gn 12,1-4) começa a história da reconciliação do gênero humano com Deus, com seu próximo e com o criado, pela via da obediência ${ }^{9}$. Essa é a temática da segunda parte do

\footnotetext{
Cf. SKA, Jean-Louis. O Antigo Testamento, p. 35.

Cf. CIMOSA, Mario. Genesis 1-11, p. 11-14.

Cf. SKA, O canteiro..., op. cit., p. 52-59.

Cf. Ibidem, p. 62.

Cf. CIMOSA, Mario. Dio e I'uomo: la storia di un'incontro, p. 17-19.

Cf. FERNANDES, Leonardo Agostini (org.). Bíblia e Catequese, p. 51-52.
} 
livro do Gênesis, que fala dos antepassados de Israel (cf. Gn 12-50): Abraão e Sara (cf. Gn 11,27-25,11); Isaac e Rebeca (cf. Gn 25,19-26,33); Jacó e suas esposas Lia e Raquel, e seus filhos (cf. Gn 27-35); José e seus irmãos (cf. Gn 37-50).

Tudo começa com um casal de migrantes. Abraão e Sara vêm de Ur dos caldeus (cf. Gn 11,31; 15,7; Ne 9,7; Js 24,2-3). Eles atravessam a terra prometida, de Siquém e Betel até o Negueb (cf. Gn 12,6.8.9), depois descem ao Egito (cf. Gn 12,10-20). Do Egito retornam em Betel (cf. Gn 13,3-4), antes de habitarem junto ao carvalho de Mambré, próximo ao Hebrom (cf. Gn 13,18). Em seguida, são encontrados novamente no Negueb (cf. Gn 20,1-18), depois em Bersabéia (cf. Gn 21,32-33; 22,19). Sara, contudo, morre e é sepultada no Hebrom (cf. Gn 23,2).

Abraão e Sara são o protótipo do migrante que deixou seu país de origem sem jamais voltar. No caminho Deus aparece a Abraão e Ihe promete filho, bênção e terra; assegura-Ihe ainda sua proteção e companhia. No país de imigração, Abraão e Sara percorram a terra motivados pelas promessas de Deus, mas também enfrentam fome (cf. Gn 12,10), ameaças (cf. Gn 12,18-10; 20,9-13), separações (cf. Gn 13), guerra (cf. Gn 14), injustiças (cf. Gn 21,22-32) e morte (cf. Gn 19; 22 e 23). Entretanto, Deus permanece fiel e cumpre suas promessas. Embora Sara fosse estéril (cf. Gn 11,30), gerou um filho para Abraão (cf. Gn 21,1-4). Na ocasião da morte de Sara, Abraão conseguiu comprar um campo com uma gruta sepulcral (cf. Gn $23,1-20)^{10}$ e ambos foram abençoados (cf. Gn 12,17; 17,16; 20,1-18).

Isaac é um personagem mais brando. Liga-se sobretudo ao poço de Laai-Roí (cf. Gn 24,62; 25,11). Embora tenha herdado de seu pai Abraão um campo com uma gruta sepulcral (cf. Gn 23,1-20), não se fixou ali, a não ser nas proximidades de sua morte (cf. Gn 35,27-29). Protótipo do migrante interno, jamais deixou o seu país (cf. Gn 24,6; 26,2-3). Enfrentou algumas desavenças por causa de suas propriedades (cf. Gn 26,15-33), mas não há notícias de maiores dificuldades. Isaac também herdou de seu pai as promessas do Senhor (cf. Gn 25,5.11) e, ao lado de Rebeca, foi abençoado, teve filhos (cf. Gn 25,24-28) e muitos bens (cf. Gn 26,14).

Jacó é o protótipo do migrante refugiado, que sai de sua terra por causa da ameaça de morte por parte de seu irmão (cf. Gn 27,41-45; 28,1-3). Durante sua fuga, através de um sonho, o Deus de Abraão e Isaac aparece para Jacó, renova as promessas do dom da terra e de descendência numerosa, ademais Ihe assegura sua companhia, condução e cuidados (cf. Gn 28). Jacó refugia-se, então, na terra natal de sua mãe, na casa do tio materno, que virá a ser seu

\footnotetext{
${ }^{10}$ A compra do campo por Abraão foi um fato notório e sem precedentes, pois ao imigrante era permitido ter bens, mas era vetado comprar propriedade de terra no antigo oriente.
} 
sogro. Durante os vinte anos em Padã-Harã, na casa de Labão, Jacó viveu desventuras e alegrias (cf. Gn 29,1-30,1). Desventuras por ser enganado pelo sogro, de modo a casar-se com duas irmãs, por ser submetido ao trabalho servil e ingrato, por sentir-se ameaçado pelos filhos de seu sogro e pelo próprio sogro. Alegrias por casar-se com a mulher amada, por gerar doze filhos e ser abençoado por Deus.

Diante de novas ameaças no país de refúgio, Deus aparece novamente a Jacó e ordena-lhe de retornar à sua casa paterna, em sua pátria (cf. Gn 31,3). Jacó foge, então, com sua família e seus bens. Durante a fuga, Jacó foi perseguido (cf. Gn 31,22-42), estabeleceu fronteiras e acordos de paz (cf. Gn 31,42-54), foi tomado de medos avassaladores (cf. Gn 32,4-22; 33,1-4), lutou com Deus e com homens (cf. Gn 32,23-33), teve sua única filha violentada e raptada (cf. Gn 34) e viu seus filhos fazerem numerosas vítimas em Siquém, vendo-se obrigado a fugir novamente (cf. Gn 34,25-31). Na fuga para Betel perdeu a esposa amada (cf. Gn 35,19) e ganhou mais um filho (cf. Gn 35,18). Com a bênção de Deus, Jacó chegou em paz ao seu destino, em tempo de reconciliar-se com seu irmão e sepultar seu pai (cf. Gn 35,27-29).

Jacó, portanto, passa vinte anos em Harã, isto é, na Mesopotâmia, e termina sua vida no Egito, mas será sepultado na terra de Canaã (cf. Gn 50,1-13). No mesmo túmulo foram sepultados Abraão e Sara, Isaac e Rebeca, Jacó e Lia (cf. Gn 49,31).

O que Abraão foi convidado a abandonar (cf. Gn 12,1-4a), Jacó foi convidado a retomar (cf. Gn 31,3): a terra natal, a parentela e a casa paterna. Ambos são migrantes e caminham pelo desconhecido. Abraão é apresentado como paradigma da partida sem retorno, enquanto Jacó é o paradigma da partida com retorno, símbolo da astúcia, que incorpora a ética da viagem, do transitório e da adaptação às adversidades circunstanciais (cf. Gn 31,4-13).

A história de José (cf. Gn 37-50) é diferente das narrativas dos demais ancestrais, ele retrata a vida de um hebreu da "diáspora". Embora sua história de migração surja dos conflitos entre seus irmãos, tendo como consequência a venda de José a uma caravana de mercadores, o que em palavras modernas significaria tráfico de pessoas, a vida de José no Egito foi um sucesso. José tornou-se muito rico e poderoso: "hoje se diria que é o primo da América, felizardo, rico, bem colocado, capaz de ajudar os pobres membros da família que ficaram na própria pátria... a família vai ao seu encontro na 'América', quer dizer no Egito, para fugir da carestia e da fome"11, de tal modo, demonstra que o poder não serve somente para oprimir, mas para salvar, colocando-se a serviço dos menos favorecidos.

${ }_{11}^{11}$ SKA, O Antigo Testamento, op. cit., p. 44. 
Na história de José, viver no exterior não é um problema, não há dificuldades quanto à alimentação, ao culto, à língua ou aos matrimônios mistos. José se casa com a filha de um sacerdote egípcio (cf. Gn 41,45). Parece que foram esquecidas as recomendações de Abraão ao seu servo quanto ao matrimônio de Isaac (cf. Gn 24,1-4), ou de Rebeca e Isaac quanto ao matrimônio de seus filhos (cf. Gn 27,46; 28,1-2). Os conflitos familiares acabaram bem. A história de José gera esperança e coragem no povo que se encontra em situações semelhantes.

A história, todavia, nem sempre é ascendente e linear. Após a morte de José, chegou ao poder um faraó que não conheceu José e usou de seu poder para oprimir e perseguir os filhos de Israel (cf. Ex 1,8). Este tipo de política também não é estranha em nossos dias. Dependendo de quem está no comando as fronteiras tornam-se porosas, os migrantes podem entrar no país, trabalhar, construir sua vida, enquanto as autoridades fazem vistas grossas para questões de documentação e permanência. Basta que se mude de governo e de política para se empreender uma perseguição aos imigrantes, fechamento de fronteiras e deportações em massa.

Foram anos de amargura dos filhos de Israel no Egito. O faraó não queria deportá-los, porque a mão de obra era conveniente para o país, mas temia que o bem-estar acelerasse o crescimento populacional, o que poderia ser uma ameaça ao seu poder. Em decorrência disso, além de explorar a força de trabalho, estabeleceu normas de controle de natalidade para os imigrantes (cf. Ex 1-2).

Deus ouve o grito do imigrante oprimido, submetido ao trabalho servil, insano e desumano, Deus vê a que situação chegou seu povo e se compadece. Inicia-se, então, um longo relato sobre a origem do povo de Israel nascido sobre a guia de Moisés. Este se articula em quatro sessões: a história do êxodo ou saída do Egito (cf. Ex 1-15); os relatos sobre a permanência no deserto (cf. Ex 15-18; Nm 11-34); a longa permanência de Israel junto ao monte Sinai (cf. Ex 19-Nm 10); e, por fim, os quatro discursos de Moisés, pronunciados em Jericó no último dia de sua vida, que formam o quinto livro do Pentateuco, o Deuteronômio.

O caminho do antigo Israel, do Egito a Canaã, se distingue pela libertação, constituição e consagração como propriedade particular de Deus (cf. Ex 19,3-8). A eleição deste povo migrante, dentre os demais povos da terra, tem uma finalidade específica: dar a conhecer o seu Deus aos outros povos pela justiça (cf. Dt 7,1-16), o que inclui não tratar o migrante que estiver em seu meio como foram tratados quando eram migrantes ${ }^{12}$. A pedagogia divina, usada na

12 Cf. O refrão: "pois fostes imigrantes na terra do Egito" se repete em: Ex 22,20; 23,9; Lv 19,34; 25,33; Dt 10,29; 1Cr 29,25. 
eleição e condução do antigo Israel, visa conduzi-lo ao caminho da promoção do bem, da justiça, da verdade, da solidariedade e da inclusão social.

\subsection{Algumas figuras e temas relacionados à mobilidade humana}

Não é possível aprofundar aqui os numerosos exemplos de figuras e temas pertinentes presentes na Bíblia, por isso faz-se a opção de tratar algumas especificidades.

\subsubsection{Agar: mulher, mãe solteira e refugiada}

${ }^{10} \mathrm{E}$ o anjo do Senhor ainda lhe disse: "Multiplicarei numerosamente tua descendência; não se contará de tão numerosa". ${ }^{11}$ Ainda lhe disse o anjo do Senhor: "Eis que estás grávida e darás à luz um filho e o chamarás pelo nome de Ismael, porque o Senhor escutou tua aflição. ${ }^{12}$ Ele será um asno selvagem de homem: sua mão será com todos e a mão de todos será com a dele; ele habitará na presença de todos os seus irmãos". ${ }^{13}$ Então ela chamou o Senhor que lhe estava falando pelo nome: "Tu és El Roí", pois disse: "Será que ainda verei aqui, após aquele que me viu?" (Gn 16,10-13).

Sara, impedida de dar à luz, vê em sua serva a possibilidade de edificar-se (Gn 11,30; Gn 15,2-4; 16,1-2). A legislação mesopotâmica previa que uma esposa estéril poderia dar sua serva para seu marido, sendo que por essa via o filho da relação pertenceria à senhora (cf. Gn 16, 3-4; Gn 30,1-6.9-13). O plano de Sara não obteve sucesso e a fertilidade de Agar tornou-se uma ameaça (cf. Gn 16,4-5). A mesma legislação prescrevia que, se a serva estivesse grávida, não poderia ser despedida ${ }^{13}$. Para conter Agar, Sara a oprime e Agar foge (cf. Gn 16,6).

Este relato é surpreendente, pois o narrador se preocupa em apresentar a sorte de uma mãe solteira, no exterior. Agar é a serva estrangeira de Sara, proveniente do Egito. A ironia do relato é notável: uma egípcia é escrava dos hebreus na terra da promessa; quando a sequência textual fará dos hebreus escravos no Egito. Agar não participa diretamente da eleição de Abraão, portanto, não estaria incluída entre o povo herdeiro das promessas de bênção, filho e terra. Diversos epítetos acentuam a inferioridade de seu status: é mulher, é escrava, é estrangeira, porque é egípcia.

Abraão e Sara não se referem a Agar pelo nome, deste modo lhe negam até mesmo sua identidade. O anjo do Senhor, no entanto, a chama pelo nome, revelando que Deus a conhece e acompanha. O relato não hesita em fazer de Agar a primeira mulher de toda a Bíblia à qual Deus faz uma promessa semelhante à de Abraão: "Multiplicarei numerosamente tua descendência; não se contará de tão numerosa" (Gn 16,10; 22,17); e anuncia o nascimento de um filho. O nome do filho de Agar é Ismael, que significa "Deus ouve". Embora o

${ }^{13}$ Cf. TEUBAL, Savina J. Hagar the egyptian, p. 73-86. 
relato não apresente o modo como Agar dirigiu-se a Deus, sabe-se que ela foi ouvida na sua aflição. Deus ouve as orações mudas dos migrantes e refugiados oprimidos em terras estrangeiras. A salvação de Deus supera fronteiras de etnia, sexo, classe social ${ }^{14}$.

Deus ouviu os gritos da criança e o Anjo de Deus, do céu, chamou Agar, dizendo: 'Que tens, Agar? Não temas, pois Deus ouviu os gritos do menino, do lugar onde ele está. Ergue-te! Levanta a criança, segura-a firmemente, porque eu farei dela uma grande nação. Deus abriu os olhos de Agar e ela enxergou um poço. Foi encher o odre e deu de beber ao menino. Deus esteve com ele; ele cresceu e residiu no deserto... (Gn 21,17-21).

Novamente Agar reaparece, agora com o filho de sua promessa (cf. Gn 21,10-16), ambos imigrantes expulsos, a pão e água, da tenda de Abraão e Sara. Eles não são herdeiros da aliança de Deus com Abraão. Mas, para a surpresa do ouvinte-leitor, Deus ouve os gritos da criança e abre os olhos da mulher, egípcia, refugiada, sem teto, sem esperança, destroçada física e emocionalmente. A força desta narrativa é inenarrável.

No Egito, os filhos de Israel não conheciam a Deus. Moisés não conhecia a Deus. Tanto que Moisés pergunta o nome de Deus. Agar, a refugiada sem destino certo, dá um nome para Deus: "Tu és o El-Roi" (Gn 16,13), que significa o "Deus que vê". De fato, Deus viu Agar e a fez ver, quando ela já não via. A experiência de Agar não é diferente da experiência de tantos migrantes. Quantos migrantes e refugiados relatam que só chegaram ao destino por graça de Deus, que Deus foi a presença e a única certeza que os fortalecia e acompanhava durante os percalços da travessia? ${ }^{15}$

A história se repete, mas ao contrário. Os filhos de Israel estão no Egito, sob o julgo de um faraó extremamente opressor:

Muito tempo depois, morreu o rei do Egito, e os israelitas, gemendo sob o peso da servidão, gritaram: e do fundo da servidão o seu clamor subiu até Deus. E Deus ouviu os gemidos; Deus lembrou-se de sua aliança com Abraão, Isaac e Jacó. Deus viu os israelitas e se fez conhecer... (Ex 2,2325).

No diálogo com Moisés, o Senhor diz:

Eu vi, eu vi a miséria do meu povo que está no Egito. Ouvi o seu grito por causa de seus opressores; pois eu conheço as suas angústias. Por isso, desci a fim de libertá-los da mão dos egípcios, e para fazê-los subir desta terra para uma terra boa e vasta, a terra que mana leite e mel.... vai, pois, e eu te enviarei ao Faraó, para fazer sair do Egito o meu povo, os Israelitas... (Ex 3,7-12).

${ }^{14}$ Cf. SKA, O canteiro..., op. cit., p. 70-72.

${ }^{15}$ Cf. SANTOS, Neuza Botelho dos. Enfrentamento Religioso em Situação de Migração: Migração e Esperança. 
Deus não é indiferente à dor e ao sofrimento do migrante, independente da nacionalidade ou religião, pertença ao povo eleito ou não. Aliás, Agar é Egípcia e Deus salvou sua vida e a de seu filho, garantindo-lhes prosperidade. Deus não é imparcial, está do lado dos fracos. Deus ouve e desce para consolar e socorrer o grito desesperado do filho de Agar, dos filhos de Israel, e dos filhos dos migrantes e refugiados aflitos sobre o peso da opressão.

À pergunta: onde está Deus, diante do sofrimento? Pode-se afirmar que Deus está com o sofredor, com o pobre, com o excluído, com o marginalizado, com o oprimido, com os migrantes e com os refugiados. Ele desce e se faz migrante com o migrante, refugiado com o refugiado. No livro de Ezequiel (cf. Ez 8,1-18), o profeta narra a glória de Deus deixando o templo para ir ao encontro dos exilados.

Não basta saber da realidade dos migrantes, é preciso ouvi-los, é preciso vê-los, é preciso senti-los. Refugiado não é um dado, não é uma quantidade. O refugiado é uma pessoa, tem um nome, uma identidade, uma história e não escolheu a situação que se encontra, por isso, assisti-los é um dever universal.

\subsubsection{Imigrante ou nativo: "todos são iguais perante a lei"}

Na Bíblia é possível encontrar diversos textos, legislativos e narrativos, que confirmam o princípio fundamental da igualdade entre todos os membros do gênero humano. Certamente, existem outros tipos de textos, com mentalidades que afirmem a superioridade de Israel sobre outras nações (cf. Dt 26,19; 28,1). Contudo, ao lado desses textos, há outros contrários, pelos quais é possível descobrir valores fundamentais para uma sociedade justa e inclusiva ${ }^{16}$.

Entre os códigos legislativos do Antigo Israel17, em relação ao imigrante (ger), o livro do Êxodo traz ao menos sete passagens em favor da igualdade legislativa entre o imigrante e o nativo ${ }^{18}$, inclusive autorizando o imigrante a participar da páscoa do mesmo modo que o nativo (cf. Ex 12,19.48.49). Quatro destas passagens estão inscritas no código da aliança (cf. Ex 20,10; $22,20 ; 23,9.13)$. A lei da Santidade traz pelo menos dezesseis artigos que tratam o imigrante (ger) como o povo da terra ${ }^{19}$. Ademais, o mandamento do amor ao próximo define o próximo como imigrante (ger: Lv 19,34; Dt 10,19). Também o livro de Números apresenta nove passagens defendendo a validade da lei tanto para o nativo, quanto para o imigrante $(g e r)^{20}$. O livro

\footnotetext{
${ }^{16}$ Cf. SKA, O canteiro..., op. cit., p. 63-64.

17 O Decálogo (Ex 20,2-17 e Dt 5,6-21); Código da Aliança (cf. Ex 20,22-23,19), comunicado pelo Senhor a Moisés no Sinai; Lei da Santidade (cf. Lv 17-26), transmitida a Moisés pelo Senhor durante a permanência do povo no deserto; Código Deuteronômico (cf. Dt 12-26), promulgado por Moisés em Moab, antes da conquista de Canaã.

${ }^{18}$ Cf. Ex 12,19.48.49; 18,2; 20,10; 22,20; 23,9.

${ }^{19}$ Cf. Lv 16,29; 17,8.10.12.13.15; 18,26; 19,10.33.34; 20,2; 22,18; 23,33; 24,16.22.

${ }^{20}$ Cf. Nm 9,14;15,14.15.16.26.29.30; 19,10; 35,15.
} 
do Deuteronômio traz diversas prescrições favoráveis ao imigrante (ger) e, em suas leis, o inclui na tríade social: o imigrante, o órfão e a viúva ${ }^{21}$. Acentuando, Deus ama o imigrante, provendo-lhe em suas necessidades, e outorga a Israel o mandamento de amar o imigrante.

Pois, o Senhor vosso Deus, que é o Deus dos deuses e o Senhor dos senhores, o Deus grande, poderoso e temível, que não faz acepção de pessoas e não aceita suborno, faz justiça ao órfão e à viúva, ama o imigrante dando-lhe pão e veste, portanto, amareis o imigrante, pois fostes imigrantes na terra do Egito (Dt 10,17-19).

Na narrativa, a voz de Deus traduz em forma de lei seu amor e seu cuidado pelo imigrante. No Código Deuteronômico (cf. Dt 5; 12-26), o órfão, a viúva e o imigrante são os beneficiários de quatorze leis de assistência e promoção social, referentes ao repouso semanal (cf. Dt 5,14), aos sacrifícios (cf. Dt 12,7.12), ao dízimo anual e aos primogênitos (cf. Dt 12,18; 14,26-27), ao dízimo trienal (cf. Dt 14,29; Dt 26,12-13), à oferenda dos primogênitos (cf. Dt 15,20), às festas de Pentecostes (cf. Dt 16,11) e das Tendas (cf. Dt 16,14), ao feixe esquecido durante a colheita (cf. Dt 24,19), à respiga (cf. Dt 24,20.21) e às primícias (cf. Dt 26,11)22. O Código Deuteronômico é um conjunto de leis orgânico, lógico e completo que indica o caminho para uma sociedade sem empobrecidos e excluídos, alternativa e solidária, projetando a possibilidade de um mundo novo e diferente.

Desse modo: "Deus faz justiça ao órfão e à viúva, ama o imigrante dando-lhe pão e veste" (Dt 10,18). Não basta, porém, ser justo com o imigrante, assegurando-lhe o mínimo para sobreviver, é preciso amá-lo (cf. Dt 10,19), porque o amor é a garantia da identidade do imigrante como pessoa humana criada à imagem de Deus (cf. Gn 1,26-27). Mais que os benefícios sociais, qualquer imigrante, independentemente de sua raça, cor ou religião, necessita de respeito, acolhida, solidariedade, reconhecimento, empatia, oportunidade. De fato, as expressões de amor são indispensáveis para superar os traumas da migração.

\subsubsection{Era migrante e me acolheste}

Das passagens neotestamentárias, a mais interessante e original sobre o estrangeiro é, sem dúvida, a cena do juízo final do evangelho de Mateus (cf. Mt 25,31-46). Nela a palavra Xenos, isto é, estrangeiro, aparece quatro vezes (cf. Mt 25,35.38.43.44). Termo que, em geral, se refere ao indivíduo que pertence a um povo diferente (cf. Mt 27,7; At 11,18; Ef 2,12.19). Deve-se considerar que à época de Jesus este termo talvez não possuísse o sentido técnico como

\footnotetext{
${ }^{21}$ Cf. Dt 10,$18 ; 14,29 ; 16,11.14 ; 24,19.20 .21 ; 26,12.13 ; 27,19$.

${ }^{22}$ Cf. KRAMER, Pedro. Estrangeiro, órfão e viúva na legislação deuteronômica, p. 247-262.
} 
se entende hoje, mas sugere uma ideia de estranheza, seja relativo à língua, ao país, ao grupo social ou à religião.

O texto de Mt 25,31-46, portanto, refere-se a uma pessoa que não é do país e que carece dos apoios necessários para manter sua vida e dignidade, por se tratar de uma pessoa deslocada. O acento recai em sua situação de insegurança e vulnerabilidade social, aspectos que confirmam o fato de que Jesus os inclui no grupo dos famintos, sedentos, nus, enfermos e encarcerados.

Acolher (synagein) implica a ideia de incluir o estrangeiro na família ou na comunidade, considerando-o como parte integral destas para todos os efeitos. Esta atitude em relação ao estrangeiro é entendida como um gesto de misericórdia, reflexo da misericórdia de Deus: "Bem-aventurados os misericordiosos, porque encontrarão misericórdia" (Mt 5,7).

A novidade desse texto se encontra na auto-identificação de Jesus com o estrangeiro que necessita de ajuda, significando que a solidariedade com o estrangeiro não é apenas um ato de justiça, tampouco unicamente uma expressão de amor, mas uma genuína solidariedade com Jesus, porque no estrangeiro, como no faminto, no sedento, no nu, no enfermo e no encarcerado, se encontra o Senhor ${ }^{23}$.

Esta passagem revela a real dignidade da pessoa do estrangeiro em situação de vulnerabilidade social. De fato, o estrangeiro é imagem e semelhança de Deus, é o próprio Cristo que vem ao nosso encontro. Cristo se vincula diretamente com essa pessoa, suscitando o desconcerto diante de algo que jamais se havia ouvido ou imaginado: "o estrangeiro sou eu". A hospitalidade se converte, por conseguinte, num dever que repercute no destino final das pessoas, um destino que dependerá do fato de terem ou não acolhido hospitaleiramente o estrangeiro.

O Senhor apresenta a acolhida ao migrante como critério de salvação, como critério chave para abrir as portas do céu. A acolhida ao migrante, nesta ótica, é via de salvação.

\section{Sugestões para o serviço pastoral com migrantes a partir e com a Bíblia}

A Palavra de Deus é o coração de toda atividade eclesial24. A Igreja, ao longo dos anos, amadureceu a reflexão da inadequação da expressão "pastoral bíblica", como uma pastoral ao lado das demais, porque a Bíblia deve ser o fundamento, o coração, a alma de qualquer atividade eclesia ${ }^{25}$. De tal modo

\footnotetext{
${ }^{23}$ Cf. CALDUCH-BENAGES, Nuria. Saboreando la Palabra, p. 61-63.

${ }^{24}$ Dei Verbum, 1.

${ }^{25}$ Cf. RETAMALES, Santiago Silva. A Palavra de Deus, p. 5-9.
} 
que hoje é mais adequado dizer "animação bíblica da pastoral"26, pois a Bíblia é o coração, enquanto princípio vital da ação da Igreja e de sua missão de anunciar Cristo e fazer acontecer o Reino de Deus.

A animação bíblica do serviço pastoral com os migrantes deve ser voltada primeiramente aos cristãos que se sentem chamados a colaborarem com essa missão da Igreja. Nesse sentido, a Bíblia, a partir de seus inúmeros testemunhos, deve ser a matéria prima para a formação dos agentes de pastoral. Recomenda-se, então, a reflexão, a oração, o confronto entre os testemunhos bíblicos e a experiência dos migrantes, a fim de preparar o cristão para atuar no mundo da mobilidade humana, praticando a caridade de Cristo para com os migrantes.

Sugere-se, ademais, intensificar a formação, pois o conhecimento e aprofundamento dos ensinamentos bíblicos são indispensáveis para a sensibilização e formação dos fiéis em geral, nas diversas paróquias e conselhos pastorais paroquiais para que descubram e vivam a espiritualidade da comunhão, da partilha, do diálogo, da acolhida, adequando-se às constantes mudanças.

A Igreja local, igualmente, precisaria compreender a importância da pastoral dos migrantes desde seus fundamentos bíblicos e estar aberta para acolher seus filhos que vêm de outras terras: testemunhando a universalidade do catolicismo; acolhendo os migrantes e os refugiados e ajudando-os a serem protagonistas na Igreja e na sociedade; motivando-os a descobrir o papel de sua cultura e religiosidade em seu caminho pessoal, na constituição de sua família e na educação de seus filhos; colaborando para que os migrantes saiam do anonimato para arriscar a proximidade, a relação, o diálogo e o reconhecimento na nova sociedade.

O conhecimento, a interiorização e assimilação dos fundamentos bíblicos são imprescindíveis para se passar de um discurso etnocêntrico para um discurso católico, de uma identidade estática para uma identidade dinâmica, de uma visão unilateral para uma visão multifacetada, do discurso da tolerância para a prática do respeito, do amor, da inclusão.

Os textos bíblicos são lentes para ver o migrante sobre a ótica de Cristo. Os textos bíblicos são, igualmente, colunas que ajudam a edificar uma igreja na qual ninguém se sinta estrangeiro: "significando que, por intermédio do Evangelho, os não-judeus são igualmente herdeiros com Israel, membros do mesmo corpo e co-participantes da promessa em Cristo Jesus" (Ef 3,6), onde os migrantes não se sintam estrangeiros: "já não sois estrangeiros e peregrinos, mas concidadãos dos santos, e sois da família de Deus" (Ef 3,19).

${ }^{26}$ Cf. SALAZAR, Gabriel Naranjo. Da Pastoral Bíblica à Animação Bíblica da Pastoral, p. 38-45; RETAMALES, Santiago Silva. A animação Bíblica da Pastoral, p. 9-23. 
Em diversos textos Jesus está dialogando com estrangeiros: a mulher siro-fenícia (cf. Mt 7); a samaritana (cf. Jo 5); o centurião de Cafarnaum (cf. Lc 7,1-10; Mt 8,5-13); Maria de Magdala (cf. Jo 20). O agir de Jesus, numa sociedade multicultural é em si mesmo uma sugestão para o serviço pastoral com os migrantes: promover diálogos que tornem possível a convivência entre as diversas expressões culturais, deixar seguranças "dogmáticas" para ir ao encontro do outro, acolhê-lo, escutá-lo e interagir com ele.

No âmbito do pluralismo religioso e cultural, o diálogo possibilita o conhecimento e o enriquecimento recíproco, superando as fronteiras da ignorância, da intolerância, dos preconceitos. Dialogar significa reconhecer e respeitar o outro como pessoa, seus valores e convicções, sem necessariamente abrir mão de sua própria identidade, cultura ou fé. O diálogo é um espaço privilegiado onde os corações se abrem ao acolhimento e partilha da Palavra de Deus, enquanto anúncio da vitória do amor sobre o ódio, da vida sobre a morte.

\section{Conclusão}

A Bíblia oferece um vasto e rico campo de abordagens para a temática da migração ${ }^{27}$. Os principais filões - o reconhecimento da condição de imigrante, a relação com os imigrantes, o amor de Deus para com o migrante, fazendo-se migrante com os migrantes - estão intrinsecamente interligados e percorrem transversalmente as escrituras. A centralidade do tema migratório é confirmada pela significativa presença de motivos a ele relacionados: a terra, o sair e entrar, o caminho, a peregrinação, o viver como imigrante na terra, hospitalidade e acolhimento, a legislação do estrangeiro, a diversidade dos povos e dos idiomas, as relações com os povos vizinhos, e, sobretudo, a revelação de um Deus itinerante, que habita numa tenda e caminha com seu povo.

O registro das experiências do povo de Deus, com suas etapas bem definidas saída do Egito e exílio da Babilônia, bem como a localização geográfica da terra prometida numa faixa territorial que desde sempre foi um corredor de passagem, confirmam a relevância e a centralidade do tema da mobilidade humana para o testemunho bíblico. Ademais são numerosas as figuras positivas de imigrantes que o testemunho bíblico oferece: os hospedes de Abraão, Agar, a estrangeira Tamar, a viúva de Sarepta, o Sírio Naamã, a moabita Rute, os habitantes de Nínive, a Samaritana, a mulher estrangeira, o oficial de justiça, e o próprio Cristo que afirma "Era migrante e (não) me acolheste".

\footnotetext{
${ }^{27}$ Cf. FUMAGALLI, op. cit., p. 33-62; TASSELLO, Giovanni Graziano. Teologia pastoral e migrações, p. 166-196; CAMPESE, Gioacchino. La Théologie et lês Migrations: La redécouverte d'une dimension structurelle de la foi chrétienne, p. 135-155.
} 
A pluralidade dos testemunhos bíblicos, certamente, ajuda o agente de pastoral a fazer uma leitura de fé do fenômeno da mobilidade humana e a enxergar a pessoa do migrante na ótica da revelação divina. Para o migrante, o contato com o testemunho bíblico, através de grupos de reflexão e oração, pode proporcionar a identificação com um ou outro personagem ou experiência, de modo a ver, também em sua vida, o reflexo da ação libertadora de Deus, que caminha lado a lado com os migrantes e refugiados, fazendo-se Ele mesmo migrante com os migrantes, no empenho de construir uma sociedade mais bela pela diversidade e pela prática da justiça e da solidariedade.

\section{Bibliografia}

CALDUCH-BENAGES, Nuria. Saboreando la Palabra. Navarra: Editorial Verbo Divino, 2012.

CAMPESE, Gioacchino. La Théologie et lês Migrations: La redécouverte d'une dimension structurelle de la foi chrétienne. Migrations Société, Dossier: Les catholiques et lês migrations, v. 24, n. 139, 2012, p. 135-155.

CAMPESE, Gioacchino. Não és mais estrangeira nem hóspede: A teologia das migrações no século XXI. Ciberteologia- Revista de Teologia \& Cultura, v. 8, n. 37, 2012, p. 63-94.

CIMOSA, Mario. Dio e l'uomo: la storia di un'incontro. Torino: ElleDiCi, 1998.

CIMOSA, Mario. Genesis 1-11 alle origine dell'uomo. Brescia: Queriniana, 1984.

FERNANDES, Leonardo Agostini. Rute. São Paulo: Paulinas, 2012.

FUMAGALLI, Anna. Ler a Bíblia no contexto migratório. Ciberteologia- Revista de Teologia \& Cultura, v. 8, n. 37, 2012, p. 33-62.

KRAMER, Pedro. Estrangeiro, órfão e viúva na legislação deuteronômica. REMHU, Revista Interdisciplinar da Mobilidade Humana, v. 18, n. 35, jul./dez. 2010, p. 247-264.

MARIANNO, Lília Dias. La lei e los "fuera de la lei". Ribla, n. 63, 2009, p. 45-53.

RAMMINGER, Michael. Fuga, migración y derechos sociales globales. Ribla, n. 63, 2009, p. 91-100.

ReTAMAleS, Santiago Silva. A animação Bíblica da Pastoral. São Paulo: Paulus, 2011.

RETAMALES, Santiago Silva. A Palavra de Deus. São Paulo: Paulus, 2012.

SALAZAR, Gabriel Naranjo. Da Pastoral Bíblica à Animação Bíblica da Pastoral. São Paulo: Paulus, 2011.

SANTOS. Neuza Botelho dos. Enfrentamento Religioso em Situação de Migração: Migração e Esperança. Nova Edições acadêmicas, 2015.

SKA, Jean-Louis. O Antigo Testamento. São Paulo: Paulus, 2015.

SKA, Jean-Louis. O Canteiro do Pentateuco. São Paulo: Paulinas, 2016.

TASSELLO, Giovanni Graziano. Teologia pastoral e migrações. Ciberteologia- Revista de Teologia \& Cultura, v. 8, n. 37, 2012, p. 166-196. 
TEUBAL, Savina J. Hagar the Egyptian: the lost tradition of the matriarchs. San Francisco: Haper \& Row, 1990.

Recebido para publicação em 13.09.2017 Aceito para publicação em 20.10.2017 Received for publication in September 13 $3^{\text {th }}, 2017$ Accepted for publication in October 20 $0^{\text {th }}, 2017$

ISSN impresso 1980-8585

ISSN eletrônico 2237-9843 http://dx.doi.org/10.1590/1980-85852503880005111 